\title{
Tecnologias Digitais e Geometria Espacial: Contribuições de uma Formação de Professores na Perspectiva do Ensino Remoto
}

\author{
Danilo do Carmo de Souza ${ }^{1}$, Arianny de Sousa Lira², Francisco Ellivelton \\ Barbosa $^{2}$, Juscileide Braga de Castro ${ }^{23}$
}

${ }^{1}$ Secretaria Municipal de Educação - Prefeitura Municipal de Fortaleza (PMF) - Caixa

Postal: 60.060-170 - Fortaleza, CE - Brasil

2Programa de Pós-graduação em Ensino de Ciências e Matemática (PGECM) - Instituto

Federal do Ceará (IFCE) - Caixa Postal: 60040-215 - Fortaleza - CE - Brasil

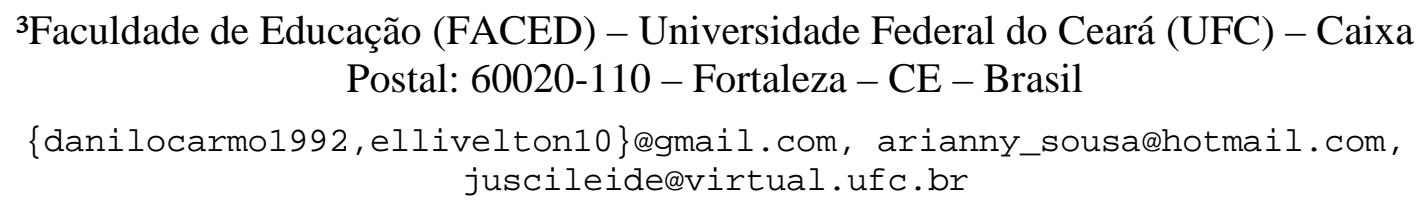

\begin{abstract}
This article aims to analyze the contributions of a remote training on the teaching of Spatial Geometry from the use of different technological tools. The training was carried out with 15 mathematics teachers, with virtual meetings, structured in 5 synchronized meetings and asynchronous activities. This qualitative research used instruments as: recorded meetings, activities developed with GeoGebra and Whatsapp protocols. The results obtained through content analysis indicate contributions related to technological appropriation and deepening; professional development and the formation of the collaboration network.
\end{abstract}

Resumo. Este artigo tem como objetivo analisar as contribuições de uma formação remota sobre o ensino de Geometria Espacial a partir da utilização de diferentes ferramentas tecnológicas. A formação foi realizada com 15 professores de Matemática, com encontros virtuais, estruturados em 5 encontros síncronos e atividades assíncronas. A pesquisa de abordagem qualitativa utilizou como instrumentos: encontros videogravados, atividades desenvolvidas com o GeoGebra e protocolos do whatsapp. Os resultados obtidos por meio da análise de conteúdo, indicam contribuições relacionadas com a apropriação e aprofundamento tecnológico; o desenvolvimento profissional e a formação de rede de colaboração.

\section{Introdução}

Os conceitos matemáticos estão presentes em diferentes contextos sociais, seja a partir da resolução de um problema mediante a utilização de operações elementares, leitura de informações em gráficos e tabelas ou na observação, reconhecimento e identificação de formas geométricas. Com isso, o estudo da matemática tem sua relevância, pois auxilia no desenvolvimento do raciocínio lógico, na comunicação, representação da realidade, observação e na tomada de decisões; facilita a resolução de situações-problemas do mundo real, além de ser considerada uma ferramenta essencial para o desenvolvimento e fundamentação de outras áreas do conhecimento [Brasil 1998; 2006; 2018]. 
Nesse contexto, é necessário que o estudante articule os diferentes conceitos presentes nas unidades de conhecimento da Matemática, a saber: Números, Álgebra, Geometria, Grandezas e Medidas, Probabilidade e Estatística, proporcionando a relação entre múltiplas representações e a diversidade de situações-problemas, concatenando propriedades e relações entre os objetos matemáticos [Brasil 2018]. Contudo, pesquisas apontam dificuldades, ausências e limitações nos processos de ensino e da aprendizagem de conceitos geométricos na Educação Básica, seja na perspectiva da formação de professores, no currículo, metodologias, ferramentas e materiais de apoio [Lorenzato 2006; Barbosa 2011; Heck 2019; Rodrigues e Kaiber 2019].

Considerando os cenários adversos, como a crise vivenciada durante a pandemia do novo coronavírus, a sociedade, em especial a escola, precisou reinventar-se com o objetivo de promover e (re)criar ambientes virtuais de aprendizagem. Essa nova reconfiguração, denominada por Ensino Remoto, refere-se a uma mudança temporária nas práticas pedagógicas em espaços físicos, e, portanto, nos processos de ensino e de aprendizagem permeados por plataformas síncronas e assíncronas: Zoom ${ }^{1}$, Google Classroom $^{2}$, Google Meet ${ }^{3}$, Whatsapp ${ }^{4}$, e-mails, redes sociais, dentre outras [Alves 2020; Arruda 2020].

Nesse contexto, tem-se como questão norteadora deste estudo: que contribuições emergem de uma formação de professores acerca do ensino de Geometria Espacial baseada no ensino remoto? Partindo deste questionamento, este artigo tem como objetivo analisar as contribuições de uma formação remota sobre o ensino de Geometria Espacial a partir da utilização de diferentes ferramentas tecnológicas.

Isso posto, esta pesquisa organiza-se em cinco seções sintetizadas a seguir: os elementos introdutórios, já apontados, seguido do referencial teórico, os procedimentos metodológicos e o contexto da pesquisa, análise e discussão dos resultados e, por fim, tecemos as considerações finais. A seguir, apresentar-se-á uma discussão sobre o ensino e a aprendizagem de Geometria mediados pelas Tecnologias Digitais de Informação e Comunicação (TDIC).

\section{Formação de professores em Geometria Espacial no contexto do ensino remoto}

Com o propósito de se continuar com atividades, cursos e aulas no período de pandemia, as mais diversas instituições e programas recorreram ao ensino remoto. O Ensino Remoto é uma solução rápida e descomplicada de se poder dar continuidade aos estudos e pesquisas, neste período de adaptação em que a Educação se encontra.

Pensando nesta realidade, não se pode confundir Ensino Remoto com Educação a Distância. Costa (2017) define Educação a Distância como sendo uma modalidade de ensino que é mediada por Tecnologias Digitais de Informação e Comunicação (TDIC) que possibilitam a comunicação entre docentes e discentes, mesmo estando em ambientes físicos diferentes, possibilitando que cada um faça seu próprio horário de estudo e escolha o melhor lugar para estudar, como em casa, em bibliotecas e/ou em lanhouses, por exemplo. Por outro lado, tem-se o ensino remoto, que se realiza por meio de atividades

\footnotetext{
${ }^{1}$ https://zoom.us/pt-pt/meetings.html

2 https://classroom.google.com/u/0/h?hl=pt-BR

${ }^{3}$ https://meet.google.com/

${ }^{4}$ https://web.whatsapp.com/
} 
aplicadas de modo pontual, geralmente atrelado ao ensino presencial, empregado com o uso de plataforma com recursos digitais [Alves 2020; Arruda 2020].

Considerando o atual contexto, o ensino remoto tem sido a melhor alternativa. Contudo, é preciso considerar a escolha de ambientes e ferramentas adequadas e que possam potencializar as relações de ensino e aprendizagem. Castro (2016) explica que as tecnologias digitais possibilitam mais agilidade em construções de gráficos, de tabelas e de outras representações; viabilizam a comunicação e a interação entre as pessoas, assim como podem potencializar a aprendizagem, quando exploram múltiplas representações. As potencialidades das TDIC dependem da mediação do professor, que, a depender de sua abordagem, pode favorecer à construção de significados e, como consequência, conseguir o engajamento dos estudantes [Castro 2016].

Neste sentido, estas abordagens precisam favorecer a investigação, a colaboração e o desenvolvimento de diferentes habilidades e competências, diferenciando-se, portanto, de abordagens tradicionais. Documentos norteadores do currículo das escolas brasileiras, como a Base Nacional Comum Curricular (BNCC), preconizam que a escola possibilite o desenvolvimento da cultura digital, que inclui não apenas a utilização, mas a construção de tecnologias digitais de forma crítica, significativa, reflexiva e ética [Brasil 2018]. Para isso, os professores precisam estar preparados a desenvolver novas abordagens metodológicas, possibilitando a produção do conhecimento pelos estudantes.

Considerando a importância de aprender fazendo, Lira, Leitão e Castro (2019) realizaram uma oficina com professores, com o objetivo de criar Recursos Educacionais Digitais (RED) de Matemática com o Scratch. A abordagem da oficina baseou-se no construcionismo, ou seja, em aprender fazendo. Durante o processo de criação dos RED, as pesquisadoras observaram que, além dos professores se apropriaram da ferramenta, estes perceberam o processo vivenciado na oficina como uma metodologia a ser desenvolvida na escola. Verificou-se ainda o empoderamento dos professores que vislumbraram a construção de seus próprios RED.

Ainda que a formação promovida a partir da oficina realizada por Lira, Leitão e Castro (2019) tenha trazido resultados significativos, principalmente relacionados à metodologia utilizada, esta formação não foi centrada em nenhum conteúdo específico da Matemática. Considera-se que os diferentes conteúdos da Matemática possuem especificidades que podem incorrer em abordagens e/ou ferramentas diferenciadas. Destacam-se, aqui, as aprendizagens de conteúdos relacionados à Geometria Espacial ao longo das etapas escolares, como indicar características de figuras tridimensionais, associar figuras espaciais e suas planificações, cálculos de volume, de capacidade ou de massa [Brasil 2018], e a construção do conhecimento no campo de visão espacial, representação espacial e imaginação espacial [Garrido e Leyva 2005].

Decerto, há importância da formação docente amparada na prática profissional, para que o processo de ensino e aprendizagem de conceitos geométricos aconteça de forma eficaz, e assim o aluno não venha a ter dificuldades futuras. Camponez, Ponté e Barrére (2017) reforçam que atualmente existem diversas iniciativas que possibilitam, por meio da formação continuada, auxiliar os educadores que buscam utilizar inovações no ensino, bem como oportunizar práticas pedagógicas em diversas áreas, incluindo o ensino de Geometria.

Moita e Viana (2019) explicitam que é necessário que o estudante possua a capacidade de visualização, de interpretação e de entendimento, possibilitando a 
abstração de figuras tridimensionais, o uso de suas propriedades e o manuseio dessas figuras. Os autores ainda reforçam que a prática metodológica deva comportar o uso de tecnologias digitais, que, com o devido direcionamento por parte dos professores, venha a ser motivador e interessante para os estudantes. Portanto, a prática pedagógica do professor para o uso de tecnologias digitais requer formação. Considerando esse contexto, a seguir, apresentar-se-á a metodologia desta pesquisa.

\section{Procedimentos Metodológicos e o Contexto da Pesquisa}

Essa pesquisa integra um projeto de mestrado, ora em andamento, intitulado Prototipação de puzzles geométricos para o Ensino Médio, cadastrado no comitê de ética, sob parecer $\mathrm{n}^{\mathrm{o}}$ : 30075920.6.0000.5589, integrando uma das oficinas realizadas pelo Grupo de Pesquisa e Produção Colaborativa de Mídias Digitais e Aprendizagem de Matemática (PROMIDIA), vinculado à Universidade Federal do Ceará (UFC). Esta oficina teve como objetivo discutir e validar, junto a professores da Educação Básica, a proposição de atividades práticas, ancoradas no desenvolvimento de habilidades do pensamento geométrico para o Ensino Médio, com suporte das TDIC.

Os encontros e desenvolvimento das atividades foram realizados no período de 13 de Maio a 20 de Junho de 2020, sendo completamente a distância, estruturados em cinco encontros síncronos (Google Meet) e ferramentas assíncronas (Google Classroom e Whatsapp). Ademais, os materiais de discussão teórica e as construções elaboradas pelos participantes foram organizados e compartilhados em pastas no Google Drive. A execução da oficina contou com a participação de vinte professores de regiões distintas do Brasil, com diferentes níveis de formação e tempo de atuação profissional, designados aqui pela letra $\mathrm{P}$, seguido de um número (P01, P02,.., P20) para resguardar seus anonimatos.

Destarte, esta pesquisa caracteriza-se como uma abordagem qualitativa, e os instrumentos de coleta de dados foram: os encontros videogravados, formulário on-line e os protocolos registrados no grupo do whatsapp. Desse modo, os dados foram coletados em momentos, ambientes e com sujeitos diferentes. Com isso, optou-se pela análise do conteúdo como uma das técnicas para o tratamento dos dados, calcado na perspectiva de Bardin (2011). A autora designa que esse procedimento tem como objetivo a “[...] descrição do conteúdo das mensagens, indicadores (quantitativos ou não) que permitam a inferência de conhecimentos relativos às condições de produção/recepção (variáveis inferidas) destas mensagens” [Bardin, 2011, p. 42].

Explicitados os procedimentos metodológicos, discorre-se sobre os resultados e a análise desses dados.

\section{Análise e discussão dos resultados}

Nesta seção, apresentam-se os resultados alcançados. O caminho percorrido em busca do objetivo compreende a identificação de categorias que emergiram durante os encontros da oficina, os quais se encontram organizadas em: [1] apropriação e aprofundamento tecnológico; [2] desenvolvimento profissional e [3] formação de rede de colaboração.

\subsection{Apropriação e aprofundamento tecnológico}

A práxis pedagógica e a cobrança por mudanças no ambiente educacional fazem com que ocorra uma busca, por parte dos professores, de mudanças em sua metodologia, 
apresentando procedimentos didáticos e abordagens com objetivo de engajar os estudantes, e, assim, tornar efetiva a construção da aprendizagem.

Com isso, durante os encontros, foi evidenciada a dimensão prática a partir da aplicação de materiais manipulativos, tecnológicos e contextualizados com a realidade dos estudantes nas aulas de matemática. Destarte, essa prática oportunizou a apropriação do software GeoGebra, já que os cursistas manipularam a ferramenta e desenvolveram atividades envolvendo construção de sólidos a partir da composição de sólidos menores, possibilitando a criação de quebra-cabeças geométricos em práticas utilizando o software, além da imersão no processo de prototipação como estratégia facilitadora para a compreensão de conceitos geométricos.

O processo de prototipação, por meio das atividades manipulativas, suscitou a compreensão do uso do software GeoGebra, e práticas que propiciem aulas participativas e dinâmicas, nas quais os estudantes manipulam e realizam inferências, conjectura, proposições por meio de recursos digitais. Ademais, tais ferramentas auxiliam no desenvolvimento de habilidades do pensamento geométrico, por exemplo: espaço, forma, visualização e representação de figuras geométricas. O participante P01 evidencia essa percepção em sua fala: “Acredito que o GeoGebra agrega a visualização do objeto construído no material manipulável no espaço 3D” (Informação verbal P01).

No que concerne ao aprofundamento tecnológico, cabe salientar que as discussões revelaram contribuições tanto para cursistas quanto formadores, já que vivenciaram situações que desencadearam na mobilização de conhecimentos referentes à projeção de sólidos em outro plano, translação dos sólidos usando vetores ou controles deslizantes, movimentação dos sólidos nos planos 2D e 3D, e em diferentes orientações de eixos, mecanismos proporcionadas pelo software GeoGebra. Ademais, a aprendizagem dessas funcionalidades deu-se de forma colaborativa, como aponta P10 "Professor, assisti muito seus vídeos, anotei seu passo a passo e de outros colegas também, mas esta questão de transladar por vetores eu aprendi com o professor P06 e depois no youtube, é claro [...]” (Informação verbal P10).

A aplicabilidade do software GeoGebra em smartphone também foi apresentado como um diferencial. Um dos participantes demonstrou a resolução de suas atividades nesse formato, reforçando o papel do celular como instrumento facilitador no processo de aprendizagem de conceitos matemáticos. Ainda nesse sentido, outro participante destaca: "Eu preciso urgentemente manusear o GeoGebra no smartphone, pois 78\% dos estudantes dispõem dele para fazer as atividades” (Informação verbal P12). O protocolo anterior chama atenção para uma das contribuições observadas nesta formação, qual seja, o empenho na busca de possibilidades práticas para remodelar as aulas que estejam mais atreladas à realidade do estudantes.

"São muitas possibilidades: focar no uso do software e/ou usar o potencial do software para explorar e construir os conceitos matemáticos.” (Informação verbal P01). Essa fala remete à apreensão da ferramenta, bem como um aprofundamento em relação a essa apropriação. Elenca-se como contribuições do processo formativo vivenciado: a visualização de possibilidades que antes não eram vistas, a utilização das tecnologias, as possibilidades metodológicas, a compreensão e as reflexões para o ensino de Geometria Espacial, que por vezes é negligenciado na escola, já que os estudantes chegam ao Ensino Médio ainda com dificuldades, pois necessitam de habilidades que deveriam ter sido desenvolvidas no Ensino Fundamental. 
IX Congresso Brasileiro de Informática na Educação (CBIE 2020)

Anais do XXXI Simpósio Brasileiro de Informática na Educação (SBIE 2020)

A seguir, apresentar-se-ão as contribuições da oficina para o campo do desenvolvimento profissional.

\subsection{Desenvolvimento profissional}

Os participantes desta oficina apontaram as possibilidades de experiências e desenvolvimento profissional, ressaltando as experiências individuais e coletivas que colaboraram para a prática docente. As aprendizagens registradas nos protocolos desta seção correspondem ao progresso adquirido no transcorrer da oficina, como apropriação de ferramentas tecnológicas, abordagens teóricas acerca dos processos de ensino e de aprendizagem e relacionamento colaborativo entre participantes de diversas regiões.

Ao final do último encontro da oficina, foi solicitado que os docentes preenchessem um formulário online com objetivo de avaliar as propostas vivenciadas pelo grupo. Um dos questionamentos presentes neste instrumental atrelava-se à prática docente descrita a seguir: A oficina suscitou melhorias em sua prática docente? Em caso positivo, de que forma? Após análise das respostas, constatou-se que, dos quinze participantes da oficina, onze responderam ao formulário de avaliação; nove assinalaram como resposta "sim, totalmente"; dois sujeitos indicaram que "sim, parcialmente"; e não houve declarações negativas. Ressalta-se como positivo o feedback apresentado diante do quantitativo total de cursistas que concluíram a formação.

Ademais, com intuito de esclarecer suas colocações acerca da formação foi disponibilizada uma caixa de texto, na qual possibilitamos que o professor explicitasse suas perspectivas acerca de seu desenvolvimento profissional após a oficina. A seguir, apontam-se alguns exemplos de argumentos considerados ${ }^{5}$ :

\footnotetext{
P06: No sentido de despertar para trabalhar a geometria espacial de forma que haja mais interrelação das suas partes com o todo na construção de quebracabeça como objeto didático auxiliar para o ensino.

P02: Auxiliou no processo de reflexão do conteúdo, sobre o porquê dele, para que finalidade, e no processo de buscar caminhos para mediar o conhecimento. P12: Pensar na inovação tecnológica como uma mola propulsora no processo de ensino-aprendizagem da matemática. Criar novos métodos didáticos para motivar os estudantes a alcançarem as competências e habilidades inerentes a um cidadão reflexivo.

P10: Com a prática de uso do GeoGebra, farei adaptações em praticamente todos os conteúdos que ensino, em Matemática.
}

À luz dos apontamentos descritos acima, pode-se inferir que, de modo geral, os participantes denotam que as atividades e discussões ofertadas durante a oficina proporcionaram reflexões sobre o desenvolvimento profissional, a partir do emprego de expressões em suas falas, por exemplo: “despertar para trabalhar”, "reflexão do conteúdo”, "pensar na inovação” e "adaptações em todos os conteúdos”, colocadas por alguns docentes, seja devido ao aprofundamento teórico e prático das atividades ou dos conceitos já trabalhados. Nesse sentido, Ponte (1994) vincula o desenvolvimento profissional como uma perspectiva que reconhece o ímpeto pela busca de aquisições de crescimento pessoal e profissional. O apontamento do participante P06 indica como este desenvolvimento progrediu no transcorrer da oficina:

P06: Possibilitou um novo aprendizado de uma nova teoria de ensino e aprendizagem (Van Hiele) que reflete, dentre outras, sobre o ensino de geometria que eu, pelo menos, não conhecia. Essa teoria fez com que, ao longo da sua apresentação na formação, pudéssemos repensar nossa posição como 
professor para o ensino de geometria, de tal modo encontrar formas que possibilitem situações mais atrativas de ensino para o aluno, colocando-o como investigador dos objetos, como sujeito construtor de seu conhecimento (Informação verbal P06).

Reconhecer a importância da formação para sua atuação profissional, assim como refletir e perceber que outras práticas podem contribuir para um melhor resultado em sala de aula, são ações que indicam o desenvolvimento profissional destes professores. Outrossim, sustentamos que mudanças em âmbito educacional decorrem também de mudanças na postura do professor, que, por conseguinte, demanda novos modelos de formação que preconizem articulações e diálogos entre teoria e prática.

Na seção a seguir, apresentar-se-ão as contribuições feitas a partir da formação de uma rede de colaboração.

\subsection{Formação de rede colaborativa}

No decorrer da oficina, os participantes depararam-se com atividades de exploração e elaboração de produções de quebra-cabeças geométricos. As atividades foram desenvolvidas com base no livro "Vendo e entendendo poliedros: do desenho ao cálculo do volume através de quebra-cabeças geométricos e outros materiais concretos", de Kaleff (2003), sendo o diferencial dessa abordagem a aplicação da ferramenta GeoGebra para a prototipação dos puzzles e visualização das propriedade dos conceitos.

Nesse contexto, era necessário a criação de um ambiente virtual que oportunizasse a troca de experiências, discussão das resoluções e sugestões dos demais cursistas, em nosso caso o Google Classroom. A permutação de ideias entre os participantes com relação à devolutiva das atividades reforça aspectos colaborativos, e as experiências de aprendizagem adquiridas com o auxílio dos colegas, indicam como positiva essa interação, como aponta P02: “Acredito que a troca de conhecimento e vivência foram tão ricas que vou sentir falta de aprender com os colegas.”(Informação verbal P02). Além disso, a participação dos professores dava-se por meio de mensagens no formato de chat, evidenciando complementações durante as apresentações ou enquanto outros colegas ou formadores explanavam considerações sobre o encontro.

Palloff e Pratt (2004) aludem que a aprendizagem colaborativa é evidenciada a partir do momento em que os comentários e as interações ocorrem primeiramente entre os participantes. Na concepção dos autores, a interação ativa ocorre quando envolve o conteúdo programático e a comunicação pessoal, por intermédio do compartilhamento de recursos, questionamentos e significados construídos socialmente pelos participantes, tendo como intencionalidade estimular e avaliar criticamente o trabalho dos colegas a fim de juntos formalizarem um produto final. Ressaltam-se abaixo alguns verbetes de argumentos sobre a interação ativa ao longo da oficina:

P10: "Mas tenho boas notícias: reconstruí várias das minhas aulas agora no GeoGebra. O curso foi de extrema importância para aflorar nossa aprendizagem. Não tenho palavras pra descrever o quanto o curso reavivou e reabriu a minha mente para o reaprendizado do GeoGebra!! Estamos em quarentena aqui no Amazonas quanto às aulas presenciais, mas eu trabalhei todos os dias aprendendo e construindo materiais para aplicar com meus alunos no retorno das aulas presenciais. Muito obrigado por todo conhecimento e aprendizado compartilhado. Tanto pela equipe organizadora do projeto quanto pelos colegas cursistas!!”

P08: “A oportunidade de trocar experiências com profissionais de várias partes 
do Brasil, a oportunidade de ampliação dos conhecimentos sobre o GeoGebra e os puzzles geométricos, o compartilhamento de materiais e a possibilidade de refletir sobre a prática docente, sobretudo em relação à utilização de ferramentas tecnológicas no processo de ensino e aprendizagem”

São notórias, pelos relatos dos participantes, as contribuições em suas práticas pedagógicas advindas do processo formativo que ocorreu na oficina, mediante imersão em uma aprendizagem colaborativa dos professores evidenciada nas resoluções das atividades, bem como nos debates no grupo do whatsapp e nos fóruns da sala de aula, no Google Classroom.

Outra contribuição advinda da oficina foi a formação de um grupo colaborativo. Os participantes criaram um grupo de whatsapp com o intuito de possibilitar e difundir discussões, trocas de experiências, métodos e compartilhamentos de práticas pedagógicas realizadas por outros profissionais da Educação, como elenca P12: “O principal foi a possibilidade de discussão e compartilhamento das práticas pedagógicas por profissionais da educação de diversos estados do Brasil. Acredito que o nosso grupo de whatsapp deveria continuar com a troca de experiências e métodos. Um grande grupo de pesquisa em Educação Matemática e suas tecnologias.”(Informação verbal P12).

O grupo de whatsapp foi instituído a partir da fala de um participante que reforçou a importância e o interesse em criar o grupo, mesmo que não seja atrelado ao curso de prototipação a fim de facilitar a troca de materiais. P17: “[...] um grupo geral, em que a gente colocaria todos, para que a gente não perdesse o contato com ninguém, é até uma forma rápida de replicar materiais, [...] o whatsapp, pra essas coisas, é bem mais prático [...], até para uma futura pesquisa ou para um futuro novo curso [...]”. Mesmo com o encerramento da oficina, o grupo de whatsapp se mantém ativo, participativo e colaborativo. No discurso acima, é possível reconhecer ações frutíferas para além da perspectiva formativa com desejo de ampliar as discussões para outros campos teóricos.

A seguir apresentar-se-ão as ponderações finais da presente pesquisa.

\section{Considerações Finais}

A presente pesquisa aglutina discussões e contribuições a respeito da utilização de diferentes ferramentas tecnológicas em uma oficina para professores de Matemática e partiu da seguinte questão norteadora: que contribuições emergem de uma formação de professores acerca do ensino de Geometria Espacial baseada no ensino remoto?

A temática de aplicação das Tecnologias Digitais de Informação e Comunicação (TDIC) no ensino remoto, tornou-se referência em processos de ensino e aprendizagem de conceitos matemáticos. Pesquisas empíricas evidenciam a necessidade de sua incorporação aos processos de ensino e aprendizagem, já que tais ferramentas oportunizam a manipulação de conceitos e ancoram a proposição de inferências partindo de registros, por vezes, difíceis de serem construídos com lápis e papel.

Seguindo uma seleção de TDIC e conceitos de Geometria Espacial, foram apresentadas as contribuições de uma oficina intitulada de "Prototipação de puzzles geométricos para o Ensino Médio”. Ao analisar os diálogos reproduzidos nos encontros e as resoluções das atividades, e apontar contribuições de apropriação e aprofundamento das ferramentas tecnológicas aplicadas na formação; o desenvolvimento profissional e a concepção de uma rede colaborativa tanto em grupos do Google Classroom e do whatsapp, nos quais fomentam, mesmo após a finalização da oficina, a divulgação de 
experiências, estudos e cursos na mesma perspectiva. Ademais, ao final da formação uma contribuição prática e amplamente difundida entre os participantes, concernente à elaboração da produção de atividades a partir de quebra-cabeças possíveis de serem replicadas em sala de aula.

Dessarte, essa pesquisa, envolta na aplicação de TDIC na perspectiva do ensino de conceitos geométricos, envolve a prototipação e o uso do software GeoGebra, o qual pode ser uma ferramenta auxiliar e aliada do professor durante $o$ ato de ensinar, tendo em vista a progressão dos estudantes na aprendizagem e compreensão dos conceitos geométricos. Portanto, consideramos que os achados dessa pesquisa iniciam um campo recente e frutífero para o campo educacional, a saber: ensino remoto. Para estudos futuros, pretende-se expandir a oficina para novas turmas, incluindo professores dos anos iniciais do Ensino Fundamental, professores ainda em formação e com estudantes de diferentes níveis escolares.

\section{Referências}

Alves, L. (2020) Educação remota: entre a ilusão e a realidade: Remote education: between illusion and reality / Educación remota: entre ilusión y realidad. "Interfaces Científicas”, Aracaju, v. 8, n. 3, p. 348-365, 2020.

Arruda, E. P. (2020) Educação remota emergencial: elementos para políticas públicas na educação brasileira em tempos de Covid-19. "EmRede”: Revista de Educação a Distância, Porto Alegre, v. 7, n. 1, p. 257-275.

Barbosa, C. P. (2011) "Desenvolvimento do Pensamento Geométrico nos anos iniciais do Ensino Fundamental: uma proposta de ensino para professores e formadores de professores”. 2011. 65p. Dissertação (Mestrado Profissionalizante em Educação Matemática da Universidade Federal de Ouro Preto) - Universidade Federal de Ouro Preto, Belo Horizonte.

Bardin, L.(2011). “Análise de conteúdo”. São Paulo: Edições 70.

Brasil. (1998) Ministério da Educação. Secretaria de Educação Fundamental. "Parâmetros Curriculares Nacionais: Matemática”. Brasília.

Brasil. (2006) Ministério da Educação. Secretaria da Educação Média e Tecnológica. "PCN+: Ensino Médio - Orientações Educacionais Complementares aos Parâmetros Curriculares Nacionais”. Brasília, 2006.

Brasil. (2018) Ministério da Educação. “Base Nacional Comum Curricular- BNCC”. Brasília.

Camponez, L. G. B.; Ponté, J. A.; Barrére, E. (2017) “MOOC - Tecnologias Digitais para o Ensino de Geometria”. Juiz de Fora, 2017. 49p.

Castro, J. B. (2016) “Construção do conceito de covariação por estudantes do ensino fundamental em ambientes de múltiplas representações com suporte das tecnologias digitais”. 2016. 275f. - Tese (Doutorado) - Universidade Federal do Ceará, Programa de Pós-graduação em Educação Brasileira, Fortaleza (CE).

Costa, A. R. (2017) A Educação a Distância no Brasil: Concepções, histórico e bases legais. "Rios Eletrônica - Revista Científica da Faculdade Sete de Setembro”. Paulo Afonso, BA, a. 11, n. 12, p. 59-74, 2017. 
Garrido, Y. P; Leyva, L. M. L (2005). Pensamiento geométrico en los escolares primarios: un modelo didáctico para estimularlo. In: Congresso Internacional de Matemática e computação, 2005, Holguín. Anais eletrônicos... Holguín.

Heck, M. F. (2019) Considerações sobre a base nacional comum curricular (BNCC) e as unidades de conhecimento matemático. "Revista Eletrônica Científica Ensino Interdisciplinar”. Mossoró, v. 5, n. 13.

Kaleff, A. M. M. R. (2003) Vendo e entendendo poliedros: do desenho ao cálculo do volume através de quebra-cabeças e outros materiais concretos. Niterói: EdUFF.

Lira, A. S.; Leitão, D. A.; Castro, J. B. (2019) Como o Processo de Produção de Mídias pode contribuir para a Formação Docente? "Renote". Revista Novas Tecnologias na Educação, v. 17, p. 425-434, 2019.

Lorenzato, S. (2006) “Para Aprender Matemática”. Campinas: Autores Associados.

Moita, F.; Viana, L. H. (2019) Um estudo sobre as conexões entre o desenvolvimento do pensamento computacional e o ensino da Geometria. "Anais dos Workshops do VIII Congresso Brasileiro de Informática na Educação (CBIE 2019)”, [S.L.], p. 208-217, 21 nov. 2019. Brazilian Computer Society (Sociedade Brasileira de Computação SBC). http://dx.doi.org/10.5753/cbie.wcbie.2019.208.

Palloff, R.M.; Pratt, K. (2004) “O Aluno Virtual: um guia para trabalhar com estudantes on-line.” São Paulo: Artmed, 216 p.

Ponte, J. P. (1994) O desenvolvimento profissional do professor de matemática. “Educação e matemática”, p. 9-20, 1994.

Rodrigues, D. S.; Kaiber, C. T. (2019) A Geometria Espacial no Ensino Médio: contribuições da utilização de uma Unidade de Ensino e Aprendizagem (UEA). “Perspectivas da Educação Matemática”, v. 12, n. 28, p. 149-167, dez. 2019. 